\title{
Kinetic Study of the Decompositions Involved in the Thermal Degradation of Commercial Azodicarbonamide
}

\author{
J. A. Reyes-Labarta, A. Marcilla \\ Dpto. Ingeniería Química, Universidad de Alicante, Apdo. 99, Alicante 03080, Spain
}

Received 11 August 2006; accepted 20 May 2007

DOI 10.1002/app.26922

Published online in Wiley InterScience (www.interscience.wiley.com).

\begin{abstract}
The transitions and reactions involved in the thermal treatment of several commercial azodicarbonamides (ADC) in an inert atmosphere have been studied by dynamic thermogravimetry analysis (TGA), mass spectrometry and Fourier transform infrared (FTIR) spectroscopy. A pseudo-mechanistic model, involving several competitive and non-competitive reactions, has been suggested and applied to the correlation of the weight loss data. The model applied is capable of accurately representing the different processes involved, and can be of great interest
\end{abstract}

\section{INTRODUCTION}

Azodicarbonamide (ADC) is a foaming agent frequently used in the production of PVC and EVA-PE foams because its decomposition liberates a high volume of gas, which is trapped in the melt. ${ }^{1-3}$ This foaming agent is used in combination with a crosslinking agent to produce the final product. According to Stevens and Emblem ${ }^{4}$ and Lober, ${ }^{5}$ the decomposition of this chemical goes through the competitive and exothermic reaction pathways shown in

F1 Figure 1, producing solids and a gaseous mixture of nitrogen, carbon monoxide, cyanic acid, and ammonia. This liberation of ammonia restricts the use of ADCs in polymers or materials sensitive to degradations or corrosions produced by this gas.

Depending on the process conditions and the state of the product, different paths may be favored over others. $^{2,3,6}$ Typical parameters for the commercial products provided by the suppliers are the particle size, the purity, and the amount of gases (gas yield) evolved in an isothermal process at $210^{\circ} \mathrm{C}$ for 15 $\min ^{7,8}$ collected in di-octyl phthalate (DOP).

On the other hand, thermogravimetric analysis (TGA) is a very powerful technique widely used to study the thermal decomposition reactions of different solids, both of organic and inorganic nature., ${ }^{9,10}$

Correspondence to: J. A. Reyes-Labarta (ja.reyes@ua.es).

Contract grant sponsor: Generalitat Valenciana; contract grant numbers: GRUPOS03/159, GV01-42, GR01-36.

Journal of Applied Polymer Science, Vol. 000, 000-000 (2007) C 2007 Wiley Periodicals, Inc.

\section{(ख)WILEY}

InterScience in the understanding and quantification of such phenomena, including the simulation of the instantaneous amount of gases evolved in a foaming process. In addition, a brief discussion on the methodology related to the mathematical modeling of TGA data is presented, taking into account the complex thermal behaviour of the ADC. (C) 2007 Wiley Periodicals, Inc. J Appl Polym Sci 000: 000-000, 2007

Key words: chemical blowing agent; azodicarbonamide; degradation kinetics
TGA has also been used for the kinetic study and modeling of different decomposition reactions, as well as, for the identification of the materials present in a sample and to determine their proportions. ${ }^{11,12}$

Many articles ${ }^{13-16}$ have been published focusing on the complexity of the mathematical models used to represent the TGA data with complex or overlapped peaks, as well as on the relevance and physical significance of the parameters obtained. Aspects such as the quality of the experimental data, the experimental conditions, the characteristics of the experimental equipment and the sample, the procedure used for the data reduction, and the number of processes observed (i.e., the number of peaks or shoulders present in the derivative curves) are very important to develop models suitable for designing purposes. As a general consequence of such papers, it could be concluded that the model should be kept as simple as possible, which results in keeping the number of parameters as low as possible, but always allowing the model to accurately represent the experimental data with all the features observed. As stated elsewhere, ${ }^{17,18}$ a kinetic model that is capable of representing the experimental data obtained in different conditions may have physical foundations, whereas a kinetic model which is not capable of representing such data is obviously incomplete or incorrect.

The accurate knowledge of the effect of the different variables (both industrial processing and product variables) on the reactions involved in the thermal processing of polymers (grafting, crosslinking, and foaming...), as well as, the kinetic study and modeling of such processes are of paramount importance 


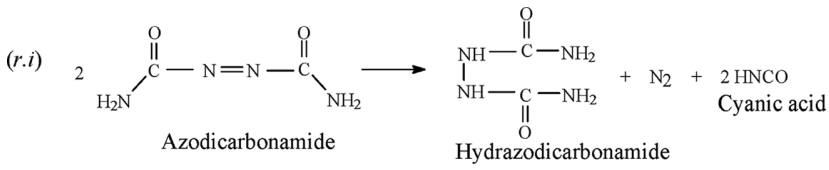

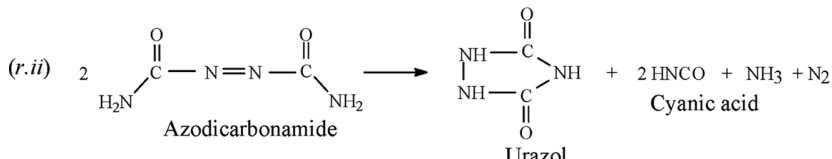

$$
\begin{aligned}
& \text { (r.iii) }
\end{aligned}
$$

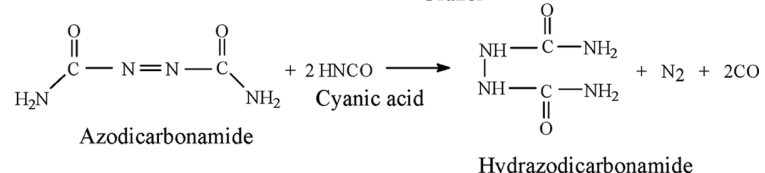

Figure 1 Reactions of decomposition of the ADC (from Refs. 4 and 5).

in the design of the moulds, in the polymer selection/formulation and in the selection of the operating variables to obtain foamed parts. On the other hand, the pyrolysis of polymer materials, studied by TGA, has received renewed attention due to the possibility of converting their wastes into useful energetic products or into valuable chemicals.

Accordingly, the objective of the present article is to study the thermal decomposition of different commercial ADCs using TGA combined with mass and IR spectroscopy, and to suggest a pseudo-kinetic model which takes into account the different reactions involved in their complex thermal decomposition, in order to allow the simulation of the instantaneous amount of gases evolved in different conditions, thus enabling the prediction of the foaming behavior.

\section{EQUIPMENT AND EXPERIMENTAL PROCEDURE}

\section{Thermobalance, mass, and IR spectrometer- Operating conditions}

The thermogravimetrical experiments were carried out using a Netzsch Thermobalance TG209 controlled by a PC system which operates under the Windows operating system. The atmosphere used was nitrogen with a flow rate of $45 \mathrm{STP} \mathrm{mL} / \mathrm{min}$, according to the specifications of the equipment.

Experiments in dynamic conditions were carried out over a range of temperatures that included the entire range of the decomposition process, 120$700^{\circ} \mathrm{C}$, with a heating rate of $10^{\circ} \mathrm{C} / \mathrm{min}$, bearing in mind that the evolution of the decomposition heat of ADC may only be slightly influenced by the heating rate when the rate exceeds $3^{\circ} \mathrm{C} / \mathrm{min} .{ }^{19}$ The mass of the sample used was around 3-4 $\mathrm{mg}$.

The experiments were replicated in order to determine their reproducibility, showing very good results with a maximum deviation between the repeated runs of about $2 \%$.
The mass spectrometer used was a Balzers MSCube-2000 with an ion source of electron impact at $70 \mathrm{eV}$. The connection between the thermobalance and the mass spectrometer is done by means of a quartz capillary of $0.220 \mathrm{~mm}$ internal diameter, maintained at $190^{\circ} \mathrm{C}$. The mass spectrometer incorporates a quadrupole axis, model QMG 421-C, with a turbomolecular pump TSH 055 that selects or sorts the ions. The intensity of four selected ions was monitored together with the thermogravimetric parameters (temperature and mass) at different times with a heating rate of $20^{\circ} \mathrm{C} / \mathrm{min}$ (according to the specifications of the equipment). The intensity data must not be compared between the different compounds because of the different sensitivities of the mass spectrometer.

The Fourier transform infrared spectrometer used was a Bruker FTIR TENSOR 27 coupled with the Netzsch Thermobalance with the followings characteristics: frequency range from 500 to $4000 \mathrm{~cm}^{-1}$ with standard $\mathrm{KBr}$ beamsplitter, $4 \mathrm{~cm}^{-1}$ of resolution, scan time of $6.6 \mathrm{~s}, 8$ scans by sample and 64 background scans, a high sensitivity DLATGS with $\mathrm{KBr}$ window as detector and a high stability interferometer with ROCKSOLID ${ }^{\mathrm{TM}}$ permanent alignment.

\section{Materials}

The experiments were carried out with different ADC foaming agents. The main characteristics of the samples used are shown in Table I. The differences among these samples of ADC are the following: sample A is a typical ADC, sample B is an activated ADC normally used for rubbers, sample $C$ is a modified ADC (formulated with PE) to be used with polyethylene (PE), polypropylene (PP), and EVA (polyethylene-vinyl acetate copolymer), and the last three samples (D, E, and F) are typical ADCs from the same manufacturer with the only difference being their particle sizes.

\section{RESULTS AND DISCUSSION}

\section{Thermogravimetric experiments}

Figure 2 shows the TGA curves corresponding to samples A, B, and C. Using sample A as reference of a typical ADC without final residue, with a temperature of maximum rate of decomposition at $240^{\circ} \mathrm{C}$ and a final temperature of decomposition at $350^{\circ} \mathrm{C}$, it can be observed that the thermal decomposition of the activated ADC (sample B) takes place at $165^{\circ} \mathrm{C}$, and also that this sample $B$ presents a final long tail over $600^{\circ} \mathrm{C}$ that gives an idea about the high proportion of the catalyst used in its formulation. Normally, this catalyst is a metal oxide such as $\mathrm{ZnO}$ or $\mathrm{MgO}$. In the case of the TGA curve for sample $\mathrm{C}$, a 
TABLE I

Main Characteristics of the Samples Used

\begin{tabular}{|c|c|c|c|c|c|c|c|c|}
\hline \multirow[b]{2}{*}{ Sample } & \multirow[b]{2}{*}{ Name } & \multirow[b]{2}{*}{ Manufacturer } & \multicolumn{6}{|c|}{ Main characteristics } \\
\hline & & & I & II & III & IV & V & VI \\
\hline A & Unicell D 200 A & Tramaco & 5.3 & 100 & 200 & 0.05 & 220 & \\
\hline B & Unifoam AZ MFE-583 & Hebron & & 75 & 143 & & 195 & \\
\hline C & Tracel DB 201/50 PE & Tramaco & & 50 & 210 & & 220 & \\
\hline D & Porofor ADC/S-C2 & Polymer additives & 7 & 99.1 & 214 & 0.05 & 228 & 1.65 \\
\hline $\mathrm{E}$ & Porofor ADC/M-C1 & Polymer additives & 4.5 & 99.1 & 214 & 0.05 & 228 & 1.65 \\
\hline $\mathbf{F}$ & Porofor ADC/L-C2 & Polymer additives & 3.5 & 99.1 & 214 & 0.05 & 228 & 1.65 \\
\hline
\end{tabular}

Properties: I, size $(\mu \mathrm{m})$; II, wt \% ADC; III, peak decomposition temperature $\left({ }^{\circ} \mathrm{C}\right) ; \mathrm{IV}, \%$ ashes; $\mathrm{V}$, gas yield $\left(\mathrm{cm}^{3} / \mathrm{g}\right.$, isothermal at $210^{\circ} \mathrm{C}$ during $\left.15 \mathrm{~min}\right)$; VI, density $\left(\mathrm{g} / \mathrm{cm}^{3}\right)$.

second main decomposition reaction over the $50 \%$ of weight fraction can be observed, corresponding to the decomposition of the PE (in the $400-500^{\circ} \mathrm{C}$ temperature range) that has been used to formulate this commercial ADC.

F3,AQ5 As an example, Figure 3 shows the DTGA (dw/dt) curve for sample F. This type of representation facilitates the identification of the reactions, mainly because small changes in TGA curves are magnified in the corresponding DTGA curves. This DTGA curve clearly shows three main peaks corresponding to at least three different reactions.

F4 Figure 4 shows the TGA curves for samples D, E, and $\mathrm{F}$ in order to consider the influence of the particle size in the thermal decomposition of ADCs. As can be observed, the general shape of the curves and therefore their reaction rates are similar. The only difference among the curves is that they seem to shift to lower temperatures when increasing the particle size. The origin of this fact in the exothermic decomposition of the ADC could be due to an auto-accelerating or autocatalyst effect ${ }^{1,2,6,20}$ of the global decomposition rate, as a consequence of the heterogeneous reaction (r.iii) in Figure 1. When the ADC particle size increases, the reaction rate of this heterogeneous reac-

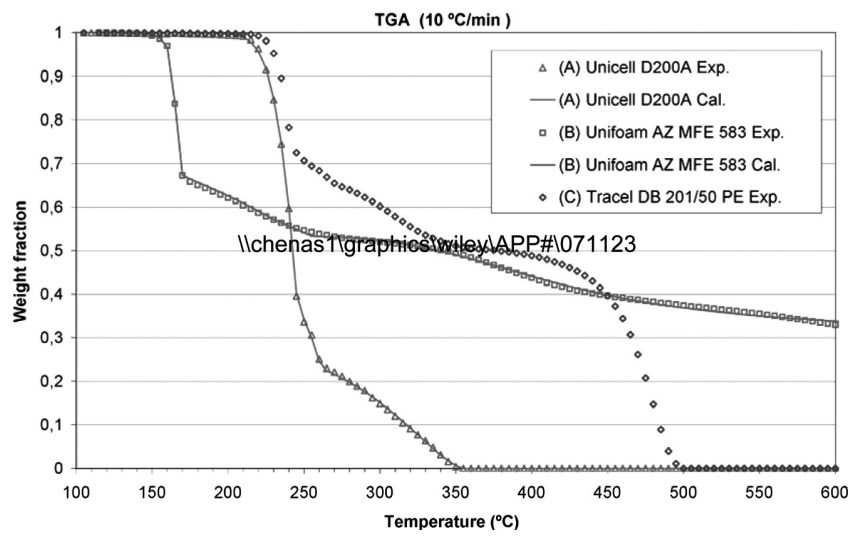

AQ5 Figure 2 TGA curves (experimental and calculated) of different ADCs (samples A, B, and C). [Color figure can be viewed in the online issue, which is available at www. interscience.wiley.com.] tion may increase due to a larger contact time of the HNCO gas (produced from reactions r.i and r.ii, Fig. 1) with the ADC particle. Consequently, a larger probability may exist for this $\mathrm{HNCO}$ gas to react with the unreacted $\mathrm{ADC}$, through reaction (r.iii), thus accelerating the degradation process.

This effect has also been observed by DSC. In this sense, Figure 5 shows the corresponding curves for these three samples when scanned in a Perkin Elmer ${ }^{\circledR} \mathrm{DSC7}$, at $10^{\circ} \mathrm{C} / \mathrm{min}$ and in an inert atmosphere. As in TGA experiments, the curves shift to higher temperatures when decreasing the particle size of the ADC (samples D, E, and F, respectively), thus corroborating this behavior.

This fact could result contradictory to the data provided by some manufactures such as Quinn ${ }^{3}$ in experiments with catalysts; but in these cases, the better contact between both solids dominates over the auto-accelerating effect as the particle size of the ADC decreases.

\section{Kinetic model and mathematical treatment of the data}

Although we are aware that the decomposition reaction of the ADC can have different chemical interme-

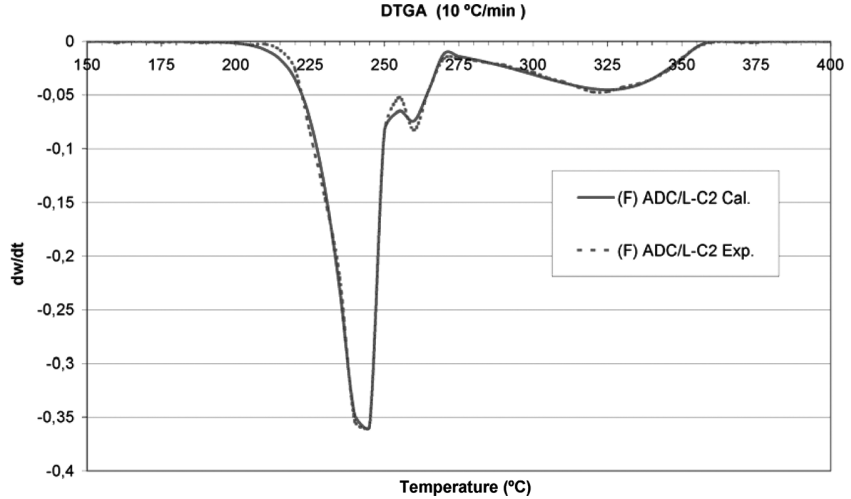

Figure 3 Experimental and calculated DTGA curves of ADC (sample F). [Color figure can be viewed in the online issue, which is available at www.interscience.wiley.com.] 


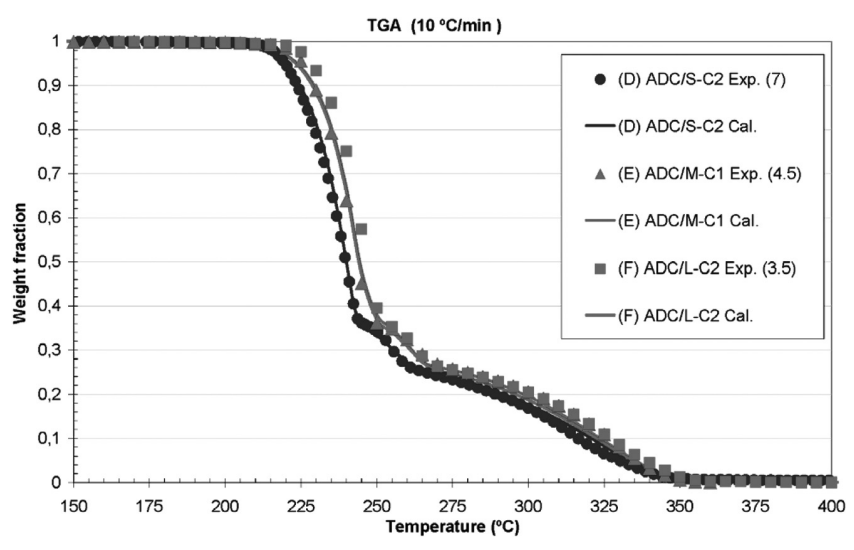

AQ5 Figure 4 TGA curves (experimental and simultaneously calculated) of different ADCs (samples D, E, and F) with different particle size (7, 4.5, and $3.5 \mu \mathrm{m}$, respectively). [Color figure can be viewed in the online issue, which is available at www.interscience.wiley.com.]

diate steps (such as nucleation reactions or radical processes), the aim of the present study is to evaluate the global pseudo-kinetic constants of the single chemical reactions (weight loss). With this simplification, the number of kinetic parameters to be optimised is kept to a reasonable level, and a very good correlation of the experimental data is still obtained. A mechanistic pseudo-kinetic model has therefore been suggested and applied to quantify and simulate the evolution of the different species present in the sample (with the temperature or time) and also to determine the amount of gases evolved, which may help in the optimization of industrial processing.

$n$ th-order kinetics is a widely accepted law for the thermal decomposition of different solid materials, and has also been used for ADC decomposition using DSC data. ${ }^{18,21-23}$ The kinetic law can be expressed as:

$$
\begin{aligned}
\frac{d w}{d t} & =-k \cdot w^{n}=-k_{0} \cdot w^{n} \cdot \exp \left(\frac{-E_{a}}{R \cdot T}\right) \\
& =-k_{\text {ref }} \cdot w^{n} \cdot \exp \left(\frac{-E_{a}}{R} \cdot\left(\frac{1}{T}-\frac{1}{T_{\text {ref }}}\right)\right)
\end{aligned}
$$

where $w$ is the weight fraction of the nonreacted sample that means the weight at the time $t$ divided by the initial weight of the sample. An Arrhenius type behavior of the rate constant $k$ has been considered, and where $k_{0}$ is the pre-exponential factor, $k_{\text {ref }}$ is the pre-exponential factor at $T_{\text {ref, }} E_{a}$ is the apparent activation energy, $R$ is the universal gas constant, $T$ is the temperature of the sample at a given time $t$, and $n$ is the reaction order. In this case, we have assumed the same kinetic law to represent the rate of the different reactions involved in the TGA experiments, and $k_{\text {ref }}$ is used instead of $k_{0}$ in order to improve the quality of the fitting and diminish the interrelation among the kinetic parameters. ${ }^{24}$
Therefore, if the pseudo-kinetic model has to explain the complex behavior of the ADC decompositions, contemplating the three different processes involved (Fig. 3), at least three different kinetic terms must be used. The scheme widely accepted $4,5,7,8$ of Figure 1 for the decomposition of the ADC, with competitive reactions having the same reactant, is not capable of explaining the three peaks observed in Figure 3 (since competitive reactions such as reactions in Fig. 1 cannot yield separated or independent peaks and consequently, these reactions could only be associated to the first peak in Fig. 3). Therefore, the proposed pseudo-kinetic model will contemplate the scheme reaction (r.i-r.iii) in Figure 1 plus two degradations of the corresponding solid products: $\mathrm{H}_{6} \mathrm{~N}_{4} \mathrm{C}_{2} \mathrm{O}_{2}$ from reactions (r.i) and (r.iii), and $\mathrm{H}_{3} \mathrm{~N}_{3} \mathrm{C}_{2} \mathrm{O}_{2}$ from reaction (r.ii). Additionally, we have considered the possibility of the formation of an intermediate compound (adsorption reaction) between the $\mathrm{HNCO}$ and the $\mathrm{ADC}$, prior to the heterogeneous reaction (r.iii), in order to consider the possibility of its accelerating effect in the global decomposition rate, which appears in samples of ADC with different size, isothermal experiments or in the treatment of polymeric samples with different amount of ADC in their formulation. ${ }^{1,2,6,20,25}$ Thus, the complete scheme suggested has a total of six possible reactions:

$$
\begin{array}{rr}
2 \mathrm{H}_{4} \mathrm{~N}_{4} \mathrm{C}_{2} \mathrm{O}_{2} \rightarrow \mathrm{H}_{6} \mathrm{~N}_{4} \mathrm{C}_{2} \mathrm{O}_{2}+2 \mathrm{HNCO}+\mathrm{N}_{2} & (\mathrm{r} .1) \\
2 \mathrm{H}_{4} \mathrm{~N}_{4} \mathrm{C}_{2} \mathrm{O}_{2} \rightarrow \mathrm{H}_{3} \mathrm{~N}_{3} \mathrm{C}_{2} \mathrm{O}_{2}+2 \mathrm{HNCO}+\mathrm{NH}_{3}+\mathrm{N}_{2} & (\mathrm{r} .2 \\
& \\
\mathrm{H}_{4} \mathrm{~N}_{4} \mathrm{C}_{2} \mathrm{O}_{2}+2 \mathrm{HNCO} \rightarrow \mathrm{H}_{4} \mathrm{~N}_{4} \mathrm{C}_{2} \mathrm{O}_{2}(\mathrm{HNCO})_{2}^{*}
\end{array}
$$

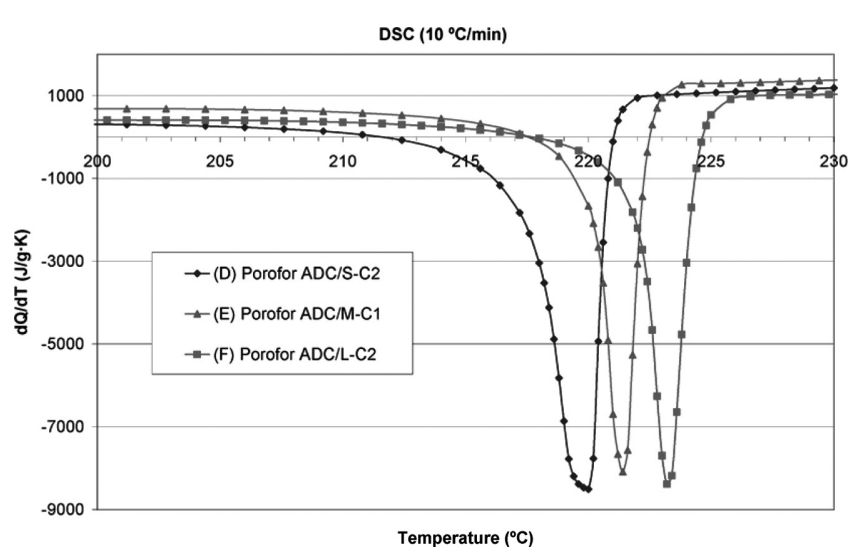

Figure 5 Experimental DSC curves of different ADCs (samples D, E, and F) with different particle size $(7,4.5$, and $3.5 \mu \mathrm{m}$, respectively). [Color figure can be viewed in the online issue, which is available at www.interscience. wiley.com.] 


$$
\mathrm{H}_{4} \mathrm{~N}_{4} \mathrm{C}_{2} \mathrm{O}_{2}(\mathrm{HNCO})_{2}^{*} \rightarrow \mathrm{H}_{6} \mathrm{~N}_{4} \mathrm{C}_{2} \mathrm{O}_{2}+\mathrm{N}_{2}+2 \mathrm{CO}
$$

$$
\begin{aligned}
& \mathrm{H}_{3} \mathrm{~N}_{3} \mathrm{C}_{2} \mathrm{O}_{2} \rightarrow \mathrm{G}_{5} \\
& \mathrm{H}_{6} \mathrm{~N}_{4} \mathrm{C}_{2} \mathrm{O}_{2} \rightarrow \mathrm{G}_{6}
\end{aligned}
$$

where, $\mathrm{G}_{r}$ are the volatiles produced in the reaction $r$.

Bearing in mind that in the thermobalance, it is not possible to distinguish between the nondecom- posed samples and the solid products, the global weight loss kinetics has to be studied:

$$
\frac{d w}{d t}=\sum_{j}^{\text {solid species }}\left(\frac{d w}{d t}\right)_{j}=\sum_{j}^{\text {solid species reactions }} \sum_{r}\left(\frac{d w_{r}}{d t}\right)_{j}
$$

The kinetic equations representing the previous scheme, if $n$ th-order kinetics is selected for all of them, are:

$$
\begin{aligned}
& \frac{d\left(\mathrm{H}_{4} \mathrm{~N}_{4} \mathrm{C}_{2} \mathrm{O}_{2}\right)}{d t}=-k_{1} \cdot\left(\mathrm{H}_{4} \mathrm{~N}_{4} \mathrm{C}_{2} \mathrm{O}_{2}\right)^{n_{1}}-k_{2} \cdot\left(\mathrm{H}_{4} \mathrm{~N}_{4} \mathrm{C}_{2} \mathrm{O}_{2}\right)^{n_{2}}-k_{3} \cdot\left(\mathrm{H}_{4} \mathrm{~N}_{4} \mathrm{C}_{2} \mathrm{O}_{2}\right)^{n_{3 A}} \cdot(\mathrm{HNCO})^{n_{3 B}} \\
& \frac{d\left(\mathrm{H}_{3} \mathrm{~N}_{3} \mathrm{C}_{2} \mathrm{O}_{2}\right)}{d t}=\frac{M_{\mathrm{H}_{3} \mathrm{~N}_{3} \mathrm{C}_{2} \mathrm{O}_{2}}}{M_{\mathrm{H}_{4} \mathrm{~N}_{4} \mathrm{C}_{2} \mathrm{O}_{2}}} \cdot \frac{1}{2} \cdot k_{1} \cdot\left(\mathrm{H}_{4} \mathrm{~N}_{4} \mathrm{C}_{2} \mathrm{O}_{2}\right)^{n_{1}}-k_{5} \cdot\left(\mathrm{H}_{3} \mathrm{~N}_{3} \mathrm{C}_{2} \mathrm{O}_{2}\right)^{n_{5}} \\
& \frac{d\left(\mathrm{H}_{6} \mathrm{~N}_{4} \mathrm{C}_{2} \mathrm{O}_{2}\right)}{d t}=\frac{M_{\mathrm{H}_{6} \mathrm{~N}_{4} \mathrm{C}_{2} \mathrm{O}_{2}}}{M_{\mathrm{H}_{4} \mathrm{~N}_{4} \mathrm{C}_{2} \mathrm{O}_{2}}} \cdot \frac{1}{2} \cdot k_{2} \cdot\left(\mathrm{H}_{4} \mathrm{~N}_{4} \mathrm{C}_{2} \mathrm{O}_{2}\right)^{n_{2}} \\
& +\frac{M_{\mathrm{H}_{6} \mathrm{~N}_{4} \mathrm{C}_{2} \mathrm{O}_{2}}}{M_{\mathrm{H}_{4} \mathrm{~N}_{4} \mathrm{C}_{2} \mathrm{O}_{2}} \cdot(\mathrm{HNCO})_{2}^{*}} \cdot k_{4} \cdot\left(\mathrm{H}_{4} \mathrm{~N}_{4} \mathrm{C}_{2} \mathrm{O}_{2}(\mathrm{HNCO})_{2}^{*}\right)^{n_{4}}-k_{6} \cdot\left(\mathrm{H}_{6} \mathrm{~N}_{4} \mathrm{C}_{2} \mathrm{O}_{2}\right)^{n_{6}} \\
& \frac{d\left(\mathrm{H}_{4} \mathrm{~N}_{4} \mathrm{C}_{2} \mathrm{O}_{2}(\mathrm{HNCO})_{2}^{*}\right)}{d t}=\frac{M_{\mathrm{H}_{4} \mathrm{~N}_{4} \mathrm{C}_{2} \mathrm{O}_{2}(\mathrm{HNCO})_{2}^{*}}}{M_{\mathrm{H}_{4} \mathrm{~N}_{4} \mathrm{C}_{2} \mathrm{O}_{2}}} \cdot k_{3} \cdot\left(\mathrm{H}_{4} \mathrm{~N}_{4} \mathrm{C}_{2} \mathrm{O}_{2}\right)^{n_{3 A}} \cdot(\mathrm{HNCO})^{n_{3 B}}-k_{4} \cdot\left(\mathrm{H}_{4} \mathrm{~N}_{4} \mathrm{C}_{2} \mathrm{O}_{2}(\mathrm{HNCO})_{2}^{*}\right)^{n_{4}} \\
& \frac{d(\mathrm{HNCO})}{d t}=\frac{M_{\mathrm{HNCO}}}{M_{\mathrm{H}_{4} \mathrm{~N}_{4} \mathrm{C}_{2} \mathrm{O}_{2}}} \cdot\left(k_{1} \cdot\left(\mathrm{H}_{4} \mathrm{~N}_{4} \mathrm{C}_{2} \mathrm{O}_{2}\right)^{n_{1}}+k_{2} \cdot\left(\mathrm{H}_{4} \mathrm{~N}_{4} \mathrm{C}_{2} \mathrm{O}_{2}\right)^{n_{2}}-2 \cdot k_{3} \cdot\left(\mathrm{H}_{4} \mathrm{~N}_{4} \mathrm{C}_{2} \mathrm{O}_{2}\right)^{n_{3 A}} \cdot(\mathrm{HNCO})^{n_{3 B}}\right)
\end{aligned}
$$

where $M_{j}$ is the molecular weight of the species $j$.

Thus, from eqs. (1)-(3), the number of parameters to fit is: $6 \times k_{\mathrm{ref}, r}, 6 \times E_{\mathrm{a}, r}, 7 \times n_{r}$, that means a total of 19 parameters. This number may appear too high but the complexity of the process, with six reactions involved in addition to the complexity of the experimental data (at least three peaks in the DTGA curves), must be considered.

These kinetic parameters have been optimized using the tool "Solver" included in the spreadsheet Excel for Windows. In all the calculations, the objective function (O.F.) considered was:

$$
\text { O.F. }=\sum_{i=1}^{N}\left[\left(\frac{d w}{d t}\right)_{\text {exp. }}-\left(\frac{d w}{d t}\right)_{\text {calc. }}\right]^{2}
$$

where $i$ represents the experimental data at temperature $T_{i}$ and at time $t_{i},\left(\frac{d w}{d t}\right)_{\text {exp. }}$ represents the experimental mass derivative with respect to the time as obtained from the TGA, and $\left(\frac{d w}{d t}\right)_{\text {cal. }}$ is the calculated value from eq. (2).

To compare different kinetic models a variation coefficient is introduced:

$$
\text { V.C. }(\%)=\left|\frac{\frac{\sqrt{\text { O.F. }}}{N-P}}{D_{\text {exp.av. }}}\right| \times 100
$$

where $N$ is the number of experimental points, $P$ is the number of parameters to be fitted, and $D_{\text {exp.av. }}$ is the average of the experimental derivatives. The integration of the kinetic equations was carried out using the Euler method.

Table III shows the corresponding parameters of fitting and VC values for the pyrolysis of the samples studied, while Figures 2 and 4 represent the experimental and calculated TGA curves together with the experimental data. As seen previously, the presence of the activating agent in the case of sample B produces an important reduction in the temperature ADC decomposition (around $75^{\circ} \mathrm{C}$ ), and this effect is now reflected in the corresponding kinetic constants with an increase in the pre-exponential factor and a reduction in the reaction order in reactions (r.1) and (r.2).

On the other hand, to check the accelerating effect previously described in samples D, E, and F due to the difference in the particle size, their corresponding TGA curves have been fitted together using the same kinetic parameters $\left(k_{\mathrm{ref}, r}, E_{a, r}\right.$, and $\left.n_{r}\right)$ and only varying the pre-exponential factor of the heterogeneous reaction (r.3), $k_{\text {ref,3, }}$ as a function of the particle size $\left(\phi_{i}\right)$. The proposed function was the ratio between the diameter of the sample and the maximum diameter tested (sample $\mathrm{D}$ in this case): 
TABLE II

Assignments of Each Signal of the Mass Spectrometer

\begin{tabular}{ccl}
\hline$m / z$ & Ion & Mainly due to: \\
\hline 12 & $\mathrm{C}^{+}$ & Carbon \\
14 & $\mathrm{~N}^{+}$ & Nitrogen \\
17 & $\mathrm{NH}_{3}^{+}$ & Ammonium \\
43 & $\mathrm{HNCO}^{+}$ & Cyanic acid \\
\hline
\end{tabular}

$k_{\mathrm{ref}, 3}^{\text {Sample i }}=\frac{\phi_{i}}{\operatorname{Max}\left(\phi_{i}\right)} \cdot k_{\mathrm{ref}, 3}^{\mathrm{sample} \operatorname{Max}\left(\Phi_{i}\right)}=\frac{\phi_{i}}{\phi_{D}} \cdot k_{\mathrm{ref}, 3}^{\text {Sample D }}$

The parameters and results obtained from the model together with the experimental data are presented in Table III and Figure 4, respectively. It can be concluded that the kinetic model proposed adequately represents the evolution of the gases as a function of the particle size of the ADC and the mechanism shown in Figure 1, including the accelerating effect.

As an example, Figure 6 shows the experimental and calculated TGA obtained for sample D (ADC/S$\mathrm{C} 2)$, where the correct fitting obtained with the proposed mechanistic kinetic model can be observed. This figure also shows the evolution of the main compounds along the dynamic experiment, such as the ADC $\left(\mathrm{H}_{4} \mathrm{~N}_{4} \mathrm{C}_{2} \mathrm{O}_{2}\right)$, the two initial solid products $\mathrm{H}_{3} \mathrm{~N}_{3} \mathrm{C}_{2} \mathrm{O}_{2}$ and $\mathrm{H}_{6} \mathrm{~N}_{4} \mathrm{C}_{2} \mathrm{O}_{2}$, the activated complex $\mathrm{H}_{4} \mathrm{~N}_{4} \mathrm{C}_{2} \mathrm{O}_{2}(\mathrm{HNCO})_{2}{ }^{*}$ and the gas HNCO.

Obviously, once the pseudo-kinetic parameters of all the reactions involved are known, it is possible to evaluate and simulate the instantaneous quantity of gas produced. By adding the different gas contributions from all the reactions along the process, it is possible to calculate the accumulated gas evolved. The results obtained for the samples studied are also shown in Table III, where it is possible to deduce that the total gas production in the dynamic thermal decomposition is around $320-340 \mathrm{~cm}^{3}$ per gram of ADC for all the ADCs studied. If we subtract from this amount of gases the values for the $\mathrm{HNCO}$ and $\mathrm{NH}_{3}$, because they are gases without a foaming character due to their solubility in DOP, where the decomposition gases of the ADC are usually collected and measured), the values obtained are quite similar to those given by the suppliers: around 220 $\mathrm{cm}^{3} / \mathrm{g}$ for the pure ADC and around $190 \mathrm{~cm}^{3} / \mathrm{g}$ for the activated ADC.

\section{Mass spectrometry and FTIR spectroscopy}

The evolution profiles of $m / z=12,14,17$, and 43 have been monitored. Table II shows the assignments of each signal to the different compounds. This assignment has been done according to the literature and taking into account the ions of the compounds expected from the pyrolysis (Fig. 1).

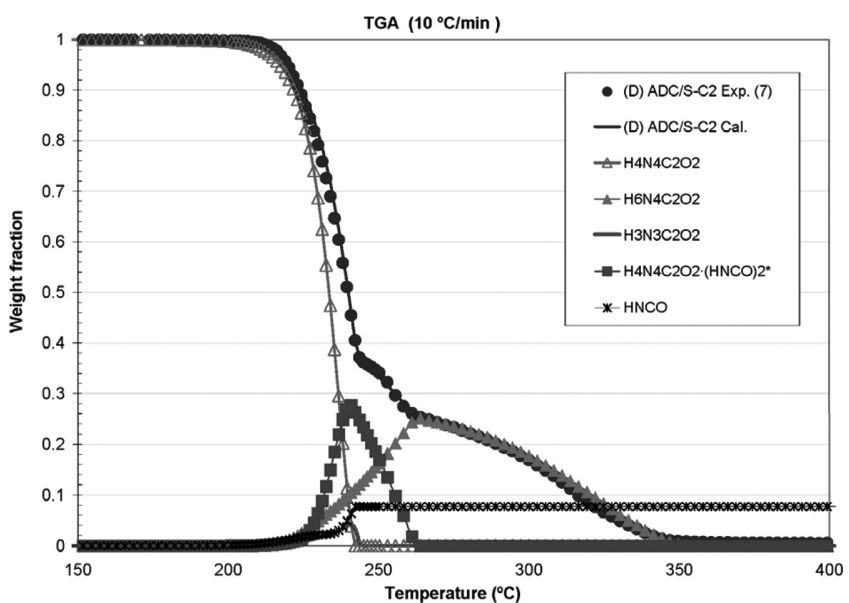

Figure 6 Experimental and calculated TGA curves of standard foaming agent (sample D). Evolution of different compounds. [Color figure can be viewed in the online issue, which is available at www.interscience.wiley.com.]

Figure 7 shows the most relevant peaks obtained in the $20^{\circ} \mathrm{C} / \mathrm{min}$ runs for the pyrolysis of one ADC (sample F), where for each ion the $y$-axis represents the total ion current (TIC) in relative units. Taking into account the peaks of the Figure 7, two main steps in the evolution of gases are present in the pyrolysis, probably corresponding to the primary decomposition of the ADC (reactions r.i-r.iii in Fig. 1) and to the following decomposition of the corresponding solid residues generated in the previous step (reactions r.5 and r.6).

In this sense, mass $\mathrm{m} / \mathrm{z}=12$ presents a single peak around $265^{\circ} \mathrm{C}$ corresponding to the emission of $\mathrm{CO}$ from the heterogeneous reaction (r.iii) in Figure 1. Mass $m / z=14$ presents a single broad peak around $265^{\circ} \mathrm{C}$ with a small shoulder at $245^{\circ} \mathrm{C}$ that correspond mainly to the emission of $\mathrm{N}_{2}$ from all reactions (r.i-r.iii) in Figure 1. Mass $m / z=43$ also

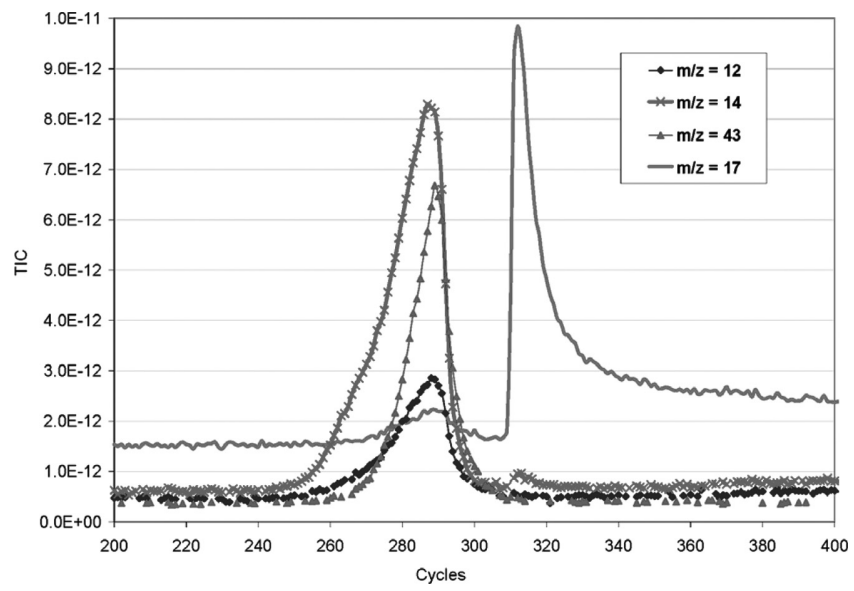

Figure 7 Mass spectrometry of pyrolysis of ADC (sample F) at $20^{\circ} \mathrm{C} / \mathrm{min}$. [Color figure can be viewed in the online issue, which is available at www.interscience.wiley.com.] 
TABLE III

Kinetic Parameters Obtained from the Fit of Experimental Data to the DTGA Curve of Foaming Agents: Samples A, B, and D/E/F

\begin{tabular}{|c|c|c|c|c|}
\hline & & A & B & $\mathrm{D} / \mathrm{E} / \mathrm{F}$ \\
\hline \multirow[t]{3}{*}{$1^{\text {st }}$ Reaction } & $k_{500}\left(\min ^{-1}\right)$ & 0.253 & 5320 & 0.241 \\
\hline & $E_{a}(\mathrm{~kJ} /$ mole $)$ & 264.8 & 267.3 & 275.6 \\
\hline & $n$ & 0.21 & 0 & 0.46 \\
\hline \multirow[t]{3}{*}{ 2nd Reaction } & $k_{500}\left(\min ^{-1}\right)$ & $1.99 \times 10^{-5}$ & $5.72 \times 10^{12}$ & $1.98 \times 10^{-5}$ \\
\hline & $E_{a}(\mathrm{~kJ} /$ mole $)$ & 294.8 & 802.0 & 282.3 \\
\hline & $n$ & 0 & 0 & 0 \\
\hline \multirow[t]{4}{*}{ 3rd Reaction } & $k_{500}\left(\min ^{-1}\right)$ & 1.730 & 0.466 & $4.23 / 2.72 / 2.11$ \\
\hline & $E_{a}(\mathrm{~kJ} /$ mole $)$ & 212.7 & 51.5 & 190.3 \\
\hline & $n_{a}$ & 1.0 & 1.0 & 1.0 \\
\hline & $n_{b}$ & 0.89 & 0 & 0.76 \\
\hline \multirow[t]{3}{*}{ 4th Reaction } & $k_{500}\left(\min ^{-1}\right)$ & $4.25 \times 10^{-2}$ & $1.91 \times 10^{-2}$ & $7.42 \times 10^{-2}$ \\
\hline & $E_{a}(\mathrm{~kJ} /$ mole $)$ & 131.8 & 13.4 & 48.7 \\
\hline & $n$ & 0 & 0 & 0 \\
\hline \multirow[t]{3}{*}{ 5th Reaction } & $k_{500}\left(\min ^{-1}\right)$ & $5.73 \times 10^{-2}$ & $1.99 \times 10^{-2}$ & $1.71 \times 10^{-1}$ \\
\hline & $E_{a}(\mathrm{~kJ} /$ mole $)$ & 251.7 & 10.8 & 12.7 \\
\hline & $n$ & 0 & 0 & 0 \\
\hline \multirow[t]{4}{*}{ 6th Reaction } & $k_{500}\left(\min ^{-1}\right)$ & $1.36 \times 10^{-2}$ & $2.89 \times 10^{-2}$ & $7.57 \times 10^{-3}$ \\
\hline & $E_{a}(\mathrm{~kJ} /$ mole $)$ & 51.9 & 80.6 & 85.5 \\
\hline & $n$ & 0.47 & 3.51 & 0.68 \\
\hline & V.C. (\%) & 0.154 & 0.083 & 0.165 \\
\hline \multicolumn{2}{|c|}{ Total gas produced $\left(\mathrm{cm}^{3} / \mathrm{g}\right)$} & 340 & 323 & $335 / 332 / 334$ \\
\hline \multicolumn{2}{|c|}{ Foaming gas yield $\left(\mathrm{cm}^{3} / \mathrm{g}\right)$} & 214 & 186 & $223 / 221 / 226$ \\
\hline
\end{tabular}

Samples D, E, and F have been correlated together using eq. (6) to introduce the particle size effect.

presents a single peak around $265^{\circ} \mathrm{C}$ corresponding to the emission of HNCO from reactions (r.i) and (r.ii). In addition, mass $m / z=17$ presents two peaks: the first one corresponds to the emission of $\mathrm{NH}_{3}$ from the reaction (r.ii) in Figure 1 and the second one that is larger, corresponds to the emission of $\mathrm{NH}_{3}$ from the total decomposition reactions (r.5 and r.6) of the initial solid residues generated previously.

These facts are confirmed by FTIR spectrometry (from 150 to $400^{\circ} \mathrm{C}$ ) where the window from 500 to $4000 \mathrm{~cm}^{-1}$ was selected, as it contains characteristic bands of the compounds to be analyzed, namely $\mathrm{CO}$, $\mathrm{NH}_{3}$, and $\mathrm{HNCO}$.

Figure 8 shows the absorbance signal versus wave number at different temperatures along the pyrolysis of sample F. In this Figure, it is possible to observe at $245^{\circ} \mathrm{C}$ the presence of the peaks corresponding to the different species generated in the primary thermal decomposition of the ADC, reactions (r.i-r.iii) in Figure 1:

-CO: $2100 \mathrm{~cm}^{-1}$

$-\mathrm{NH}_{3}: 939-960 \mathrm{~cm}^{-1}$

-HNCO: $700-850 \mathrm{~cm}^{-1}$ (NH $)$; 1120, 1270, 1730, and $1760 \mathrm{~cm}^{-1}(\mathrm{CO}) ; 1180 \mathrm{~cm}^{-1}(\mathrm{CN}) ; 1620 \mathrm{~cm}^{-1}$ (NH); $2200 \mathrm{~cm}^{-1}$ (NCO); $3500 \mathrm{~cm}^{-1}$ (NH $\gamma$ ).

On the other hand, it is possible to see that at larger temperatures such as $265^{\circ} \mathrm{C}$ all the signals have decreased, and at $325^{\circ} \mathrm{C}$ the characteristic signals of the $\mathrm{CO}$ have disappeared, while the characteristic signals of the $\mathrm{NH}_{3}$ and $\mathrm{HNCO}$ have reduced significantly.

\section{CONCLUSIONS}

The complete pseudo-kinetic model proposed, based on the mechanism first suggested by Stevens and Emblem $^{4}$ and Lober ${ }^{5}$ and checked by mass and IR spectrometry, satisfactory fits the different processes observed in the complex thermal decomposition of different commercial ADC. The model proposed is capable of representing overlapped peaks, the accelerating character of some reactions involved, explains the effect of the reduction of the decomposition temperature when increasing the particle size

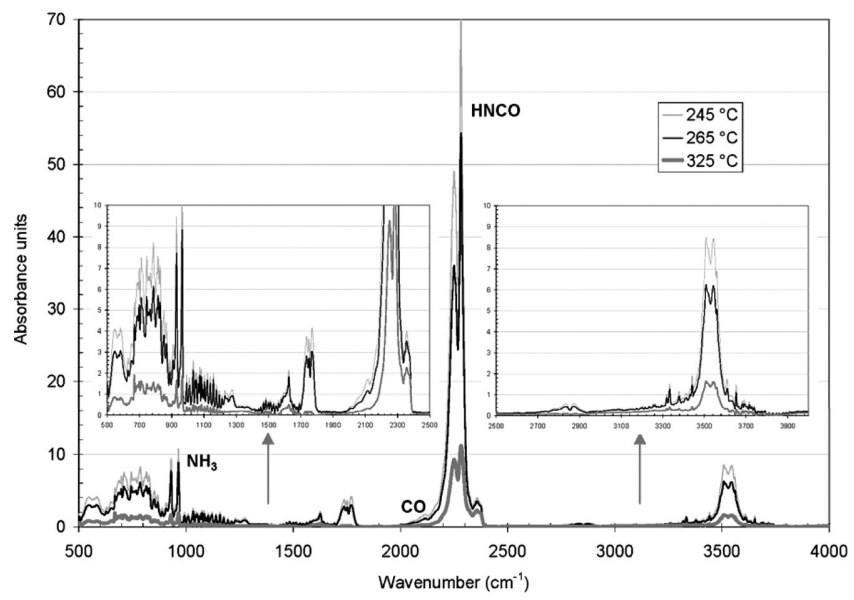

Figure 8 IR spectrometry of pyrolysis of ADC (sample F). 
and allows the simulation of the instantaneous and total amount of gases generated.

\section{NOMENCLATURE}

\begin{tabular}{|c|c|}
\hline ADC & Azodicarbonamide \\
\hline$E_{a}$ & Activation energy \\
\hline K & Rate constant \\
\hline$k_{0}$ & Pre-exponential factor \\
\hline$k_{\text {ref }}$ & $\begin{array}{l}\text { Pre-exponential factor at reference temper- } \\
\text { ature in Kelvin }\end{array}$ \\
\hline$k_{500}$ & $\begin{array}{l}\text { Pre-exponential factor at } 500 \mathrm{~K} \text { (reference } \\
\text { temperature) }\end{array}$ \\
\hline$N$ & Number of experimental points \\
\hline$N$ & Reaction order \\
\hline O.F. & Objective function \\
\hline$P$ & Number of parameters to be fitted \\
\hline PE & $\begin{array}{l}\text { Polyethylene or polyethylene domains in } \\
\text { EVA }\end{array}$ \\
\hline$R$ & Perfect gas constant \\
\hline$T$ & Temperature \\
\hline$T_{i}$ & Temperature at a given time \\
\hline & Time (s) \\
\hline V.C. & Variation coefficient \\
\hline & Mass fraction of non-reacted material \\
\hline
\end{tabular}

\section{References}

1. Lévai, G.; Nyitrai, Zs.; Meszlényi, G. Models Chem 1998, 135, 885.
2. Bhatti, A. S.; Dollimore, D. Thermochim Acta 1984, 76, 273.

3. Quinn, S. Plast Additives Compounding 2001, 3, 16.

4. Stevens, Emblem. Ind Chem 1951, 27, 391.

5. Lober, F. Angew Chem 1952, 64, 65.

6. Bhatti, A. S.; Dollimore, D. Thermochim Acta 1984, 76, 63.

7. Throne, J. L. Thermoplastic Foams; Sherwood Publishers: Ohio, 1996.

8. Klempner, D.; Frisch, K. C. Polymeric Foams; Oxford University Press: New York, 1991.

9. Cozzani, V.; Petarca, L.; Tognotti, L. Fuel 1995, 74, 903.

10. Reyes, J. A.; Conesa, J. A.; Marcilla, J. A. J Anal Appl Pyrol 2001, 58/59, 747 .

11. Grønli, M.; Antal, M. J. Jr.; Várhegyi. Ind Eng Chem Res 1999, 38, 2238.

12. Marcilla, A.; Gómez, A.; Reyes-Labarta, J. A. Polymer 2001, 42, 8103.

13. Agrawal, R. K.; Sivasubramanian, M. S. AIChE J 1987, 33, 1212.

14. Málek, J. Thermochim Acta 1992, 200, 257.

15. Mathot, V. B. F., Ed. Calorimetry and Thermal Analysis of Polymers; Hanser/Gardner Publications: Cincinnati, 1993.

16. Conesa, J. A.; Caballero, J. A.; Marcilla, A.; Font, R. J Anal Appl Pyrol 2001, 58/59, 619.

17. Marcilla, A.; Beltrán, M. Polym Degrad Stab 1995, 48, 219.

18. Marcilla, A.; Reyes, J. A.; Sempere, F. J. Polymer 2001, 42, 5343.

19. Morisaki, S.; Naito, M. J Hazardous Mater 1981, 5, 49.

20. Cronin, J. L.; Nolan, P. F. J Hazardous Mater 1987, 14, 293.

21. Sen, A. K.; Mukherjee, A. S.; Bhattacahryya, A. S.; De, P. P.; Bhowmick, A. K. J Appl Polym Sci 1992, 44, 1153.

22. Sen, A. K.; Bhattacahryya, A. S.; De, P. P.; Bhowmick, A. K. J Thermal Anal 1991, 37, 19.

23. Sen, A. K.; Mukherjee, A. S.; Bhattacahryya, A. S.; Sanghi, L. K.; De, P. P.; Bhowmick, A. K. Thermochim Acta 1990, 157, 45.

24. Himmelblau, D. M. Process Analysis Statistical Methods; Wiley: New York, 1970.

25. Reyes-Labarta, J. A.; Olaya, M. M.; Marcilla, A. J Appl Polym Sci 2006, 102, 2015. 